\title{
Research on the Implementation of Data Mining Application in Multimedia Physical Education and Track and Field Teaching based on Network Data
}

\author{
Ruijiang Liu ${ }^{1}$ and Qingying $\mathrm{Zhu}^{2^{*}}$ \\ ${ }^{1}$ College of physical education, Shandong Normal University, \\ 250014 Jinan City, China \\ ${ }^{2}$ College of physical education, Shandong University, China \\ Corresponding author: Qingying Zhu, zhuqy@sdu.edu.cn
}

\begin{abstract}
With the rapid development of information technology, multimedia network teaching has gradually become a new teaching mode of college physical education. In this paper, the authors analyze the application of data mining in multimedia education and track and field teaching based on network data. The modernization of teaching methods is one of the most important subjects in the teaching reform of physical education, by using computer assisted instruction (CAI) technology in the teaching of physical education, sports education could change from the traditional mode to modernization mode. Through the use of multimedia technology, by using the flexible teaching methods, and the advantages of voice, video and graphic combined; it can make up for the shortcomings of the traditional track and field teaching. The application of multimedia technology can be a good combination to improve students' learning enthusiasm.
\end{abstract}

Keywords: Data mining, Sports education, Track and field, Network big data

\section{Introduction}

With the rapid development of information technology, especially the popularity and application of Internet in recent years, multimedia network resources teaching has gradually become a new teaching mode of college physical education [1]. In the practice of university professional track and field teaching, on the one hand, the teaching plan of less teaching hours; on the other hand, the students' physical quality to the low professional sports recruit, must let the student in a relatively short period of time to firmly grasp the track and field sports theoretical knowledge and skills is very difficult. Therefore, we should adjust measures to local conditions to increase the flexibility of the track and field course teaching, the pertinence and practicality [2-3]. Over the years from the first-line teaching in college athletics teaching, deeply track all aspects of information query, modify, competition arrangement, classification, composition and related information of the amateur sports training collection, time-consuming, and is not standardized [4]. Although in recent years there are some computer aided teaching system, but cannot achieve the sharing of knowledge resources. To this end, we think, should use Internet, multimedia, database, image processing tools to establish a system of multimedia cyber source technology, provide a rich multimedia information platform for track and field teaching, so as to improve the sports professional students' track and field teaching quality [5].

With the development of the modernization of education, education reform has achieved great success in various fields, especially in the multimedia technology is widely used in teaching, the traditional teaching method has a great degree of change [6]. The multimedia technology involved, the flexible teaching methods, the advantages of sound, 
video and graphic together, just can make up for the shortcomings of the traditional track and field teaching, the good combination of the traditional teaching methods, improve students' learning enthusiasm, develop students' cognitive ability, help to better grasp the track and field technology. In recent years, data mining technology has been a research focus, and has achieved remarkable results [7]. With the development of information technology, more and more people have access to the data form, the emergence of a large number of multimedia data, the formation of a lot of massive multimedia database. In the past, the research of multimedia data mainly focused on the content based information retrieval, which in a certain extent solved the problem of information search and information resource discovery [8]. But people are not only satisfied with the level of information access, but also a new method to study the higher level than the multimedia information retrieval. Multimedia data mining is in a large amount of multimedia data, through a comprehensive analysis of visual features and semantics, find hidden, effective, valuable and understandable patterns, and then found that knowledge, trend and related events, provide problem solving level decision support ability for users. Multimedia technology has been involved in the field of teaching, track and field teaching in Colleges and universities as a key course to train the students' physical quality, has its own particularity, the use of multimedia technology in track and field teaching, which is intuitive, dynamic, timeliness, interactivity, promote the students' psychological development features. In track and field teaching in our colleges and universities, because the teachers' subjective factors and limitations of multimedia itself, using multimedia technology has difficulties, should correctly understand the value of multimedia technology in our country's University track and field teaching, create conditions from various aspects, improve the application of multimedia technology and expand its space effect.

\section{Multimedia Technology and Data Mining}

\subsection{Multimedia Technology}

First of all, the reform of track and field teaching means requires the intervention of multimedia technology. Teachers do not have a more comprehensive knowledge and skills, while the number of students in the case, the exchange of teachers and students will be less, the teaching effect can be imagined. According to the visual characteristics of multimedia technology, it is necessary to use multimedia technology to stimulate students' interest in track and field courses, and to implement the teaching objectives of track and field courses. Secondly, the overall development of students' body and mind, the construction and development of the track and field discipline itself requires the development of multimedia technology to provide power. Multimedia technology can develop students' psychological quality to a great extent, and the effect of aging and interaction in the classroom plays a good role in promoting the reform of track and field courses. Finally, the role of teachers and students, the main role of the play is also dependent on the implementation of multimedia technology. Multimedia technology to liberate the teacher's part of the energy, in order to better put into teaching research, and students can also more freely to practice and master the skills of track and field sports. This fully reflects the correct relationship between teachers and students in the concept of modern education. 


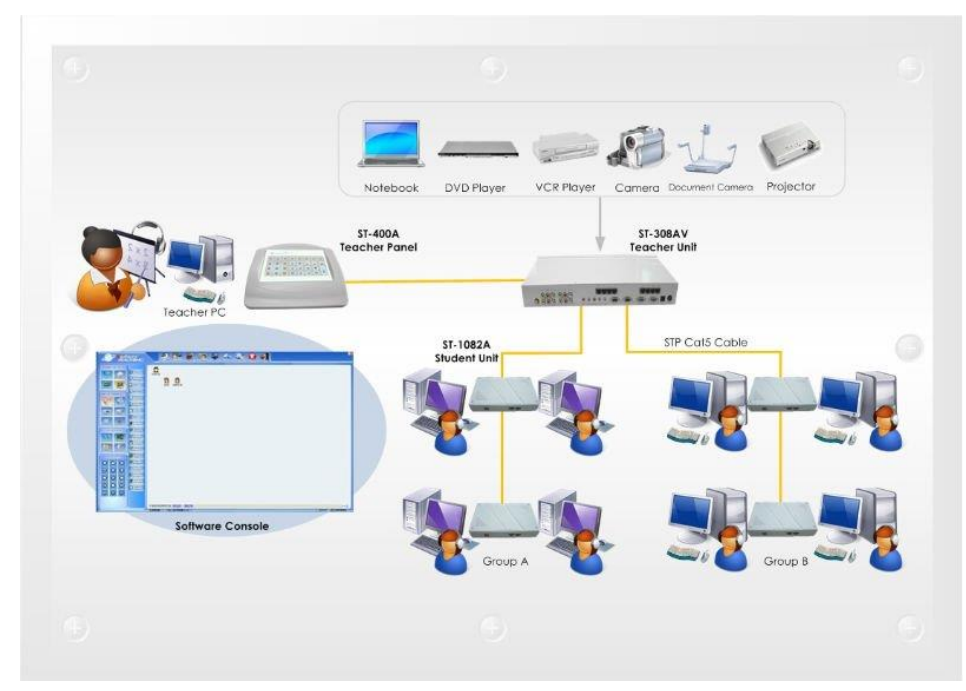

Figure 1. Multimedia Teaching

The modernization of teaching methods is one of the most important subject in the teaching reform of physical education, and computer assisted instruction (CAI) technology is applied in the teaching of physical education, physical education is an important way from the traditional mode of teaching experience to scientific, informatization and modernization. The teaching of track and field is rich in network resources. Is the intuitive teaching principle, is essential to the design of CAI courseware, in track and field teaching, can be used directly by drawing the key action, or a complete course of action can also be demonstrated; through a video input method, the students completed the field action camera down, these actions when needed playback, slow down, stop, its action is presented on the screen, the feedback analysis under the guidance of teachers, and also gives the correct action to let the students compare, can also be timely added to the standard track and field match and fragments of appreciation. This not only overcome the difficulties of teachers to repeat the demonstration, students' burnout and other difficulties, but also broaden the horizons of students, to reduce the pressure of teachers.

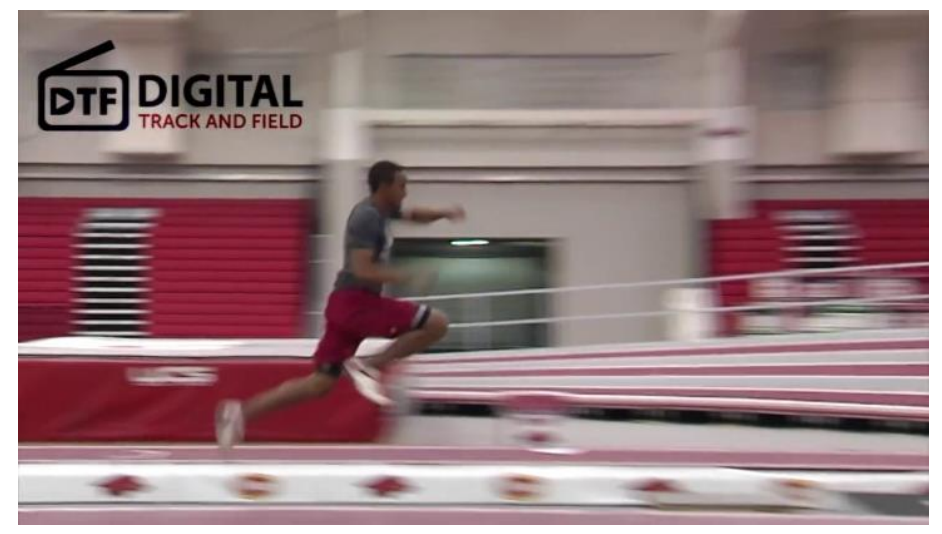

Figure 2. Multimedia Track and Field Technology Teaching

\subsection{Data Mining}

Compared with traditional data mining, multimedia data mining has several problems that need to be solved. Firstly, multimedia data is unstructured and heterogeneous. To dig in these unstructured data to obtain knowledge, these must be unstructured data into structured data, through feature extraction, feature vector as the metadata element 
database, based on data mining. Secondly, the feature vectors of multimedia data are usually tens or even hundreds, and how to make data mining is an important problem to be considered.

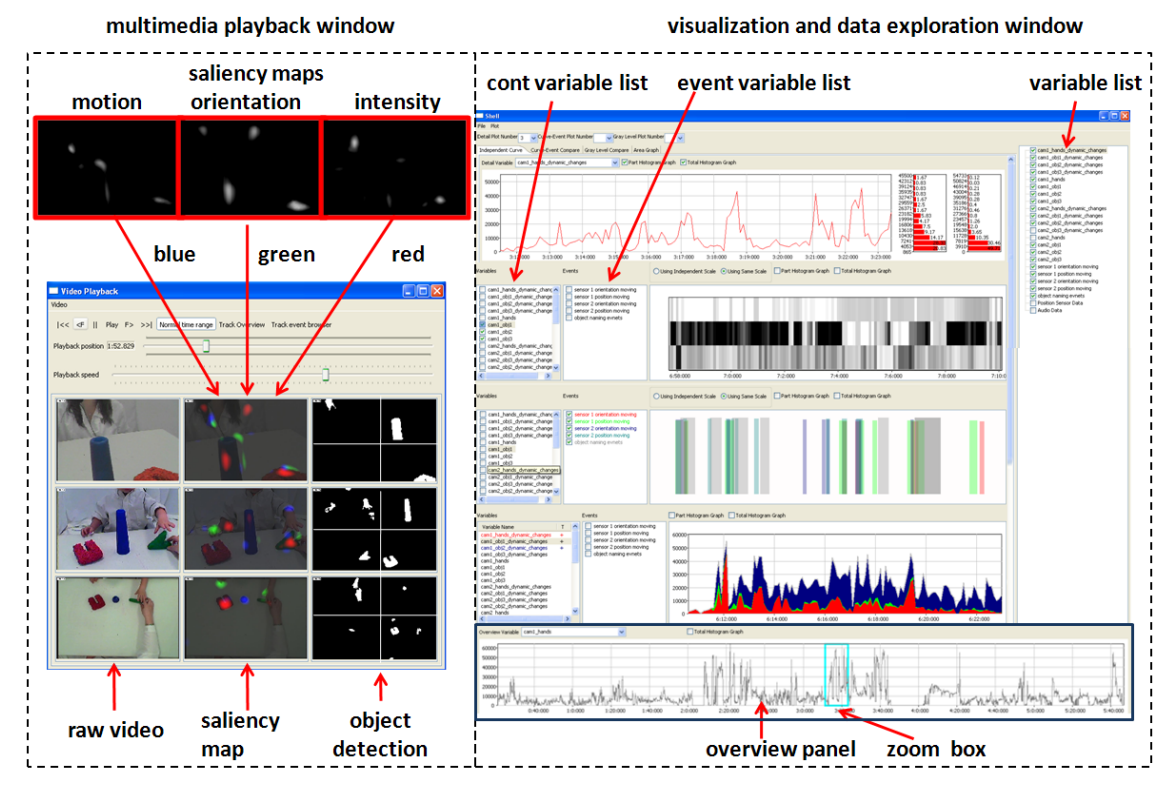

Figure 3. Multimedia Data Mining

1) Multimedia data set: Large scale multimedia data sets may contain hundreds of thousands of images, thousands of hours of video and audio, and their media structures are associated with the description of the meta database, used for visual representation and access.

2) pretreatment module: This module mainly carries on the pretreatment to the multimedia raw data, extracts the effective characteristic. The feature vector is recorded in the meta data base in the form of metadata. Metadata database is a kind of multi dimension, multi-layer and attribute database, which is required for mining.

3) mining engine: The mining engine contains a set of fast mining algorithms, such as classification, clustering, correlation, summarization, summary and trend analysis. According to the specific application, the system can select one or more corresponding mining algorithms, which can be used to mine the meta data base. The feature vectors in the meta database are usually high dimensional, while the traditional data mining method is generally suitable for low dimensional data.

4) user interface: User interface can realize the visualization of mining results and explain the interface, also can provide users with interactive interface to expand the SQL mining language. Because the audio-visual and spatiotemporal characteristics of multimedia, mining mode should be presented in new ways, such as navigation knowledge expansion and interactive problem solving process, and provide a visual interface mining results.

The support vector machine method is a learning theory of VC dimension theory and structural risk minimization principle on the basis of statistics,

$$
T=\left\{\left(x_{1}, y_{1}\right),\left(x_{2}, y_{2}\right), K,\left(x_{n}, y_{n}\right)\right\}
$$

Hypothesis existence discriminant function:

$$
f(x)=\operatorname{sgn}((\omega \cdot x)+b)
$$


Linear case, the optimal classification of the idea of the super plane can be described in Figure 4.

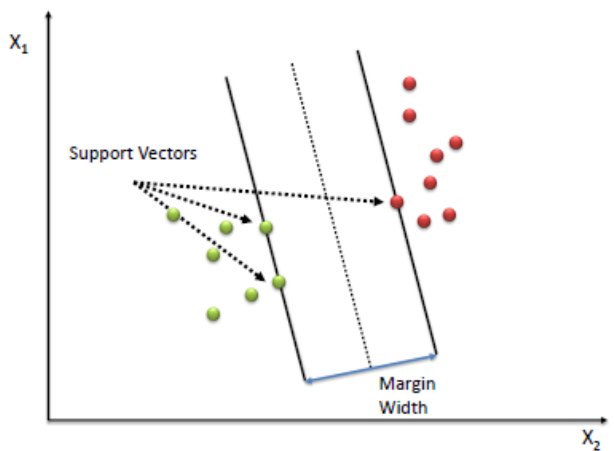

Figure 4. The Optimal Separating Hyper Plane

When the linearity is not available, there are some sample points which are not satisfied, then the formula is introduced into the:

$$
\begin{array}{cc}
\min & \frac{1}{2}\|\omega\|^{2}+c \sum_{i=1}^{n} \xi_{i} \\
\text { s.t. } & y_{i}(\omega \cdot x+b) \geq 1-\xi_{i}
\end{array}
$$

The solution can be obtained by solving the equation:

$$
\begin{gathered}
\omega=\sum_{i=1}^{n} \alpha_{i} y_{i} x_{i} \\
b=y_{i}-\sum_{i=1}^{n} y_{i} \alpha_{i}\left(x_{i} \cdot x_{j}\right)
\end{gathered}
$$

Then we get the linear discriminant function:

$$
f(x)=\operatorname{sgn}\left(\sum_{i=1}^{n} \alpha_{i} y_{i}\left(x_{i} \cdot x_{j}\right)+b\right)
$$

\section{Multimedia Network Resources in the Teaching of Track and Field}

\subsection{Network Resources System Design}

With the development of the modernization of education, education reform has achieved great success in various fields, especially in the multimedia technology is widely used in teaching, the traditional teaching method has a great degree of change. The multimedia technology involved, the flexible teaching methods, the advantages of sound, video and graphic together, just can make up for the shortcomings of the traditional track and field teaching, the good combination of the traditional teaching methods, improve students' learning enthusiasm, develop students' cognitive ability, help to better grasp the track and field technology.

Data resources are mainly composed of various kinds of information resources. System information resources stored in the information database server, the database management system Server SQL unified management. The application domain is provided by the Web 
server web pages stored in the server application system, including data management and application system to update the data query and statistics system, online test system, data resource maintenance system. When a user sends a request to use the command, the Web server receives the command and obtains the relevant data information from the corresponding database, and generates various functional pages in a dynamic form to return to the user. The user domain is composed of Web browser, facing the end user. Using the browser to access the server, to realize the courseware lesson plans to upload and download, information data query and analysis, track and field technical standard action learning and student learning and testing, etc. Multimedia network resources system using $\mathrm{B} / \mathrm{S}$ model, the use of campus network to achieve network multimedia teaching, while connected with the Internet. The specific structure of the model is shown in Figure 5.

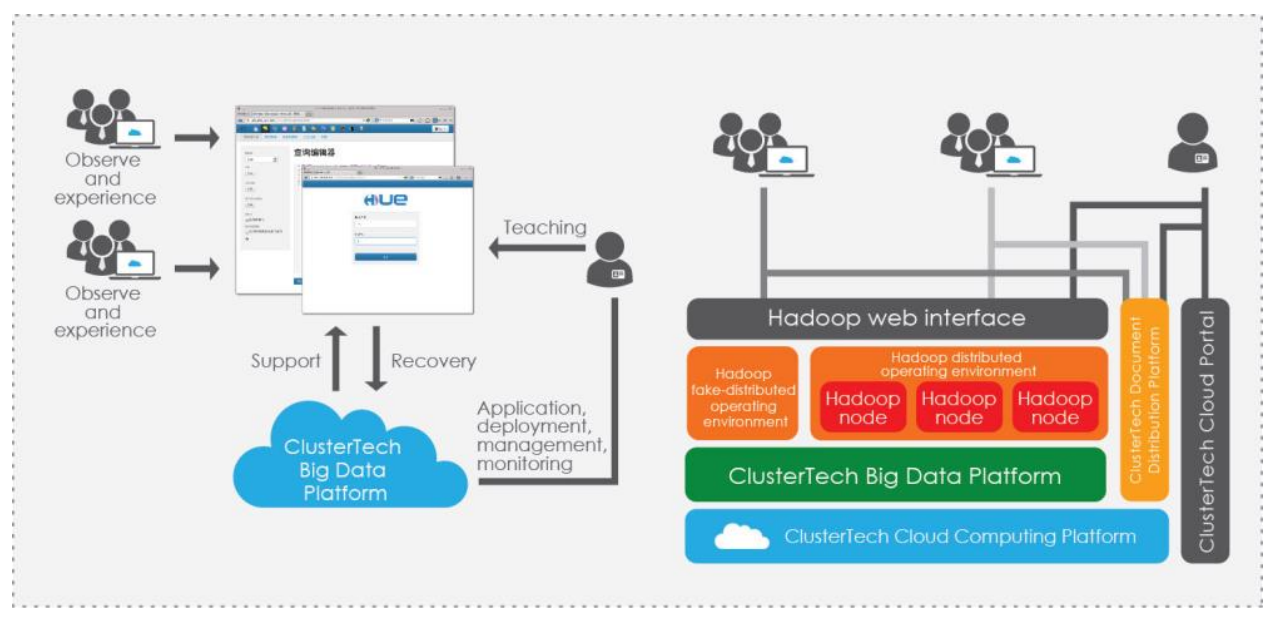

Figure 5. Network Resource System

Track and field teaching contents cumbersome, multimedia information generally involves text information, picture information, video information and audio information. The collection and collation of information data are as follows: (1) text information. For ordinary text information can be directly input or scanner; for the special text information such as art, and through the production of Photoshop. (2) picture information. Such as continuous action moving layup, the complete jumper can use a scanner or digital camera, the picture will be entered into the computer, forming the *.JPG file, and then use Photoshop to modify and zoom processing etc. (3) video information. Using digital camera to take the standard action of teachers, and then according to the actual teaching needs to be produced into the appropriate picture and video files.

\subsection{Multimedia Aided Instruction}

From the technical characteristics of track and field sports, action structure, complete the form of relatively fixed speed, a complete technology basically completed in ten seconds, or even shorter, so it is an action cycle, action integrity is strong, not easy decomposition model. So, the initial stage of learning technology in track and field of students, students of the complete lack of perceptual situation, the teacher's demonstration only for students to leave a vague idea, let students are difficult to understand and imitate, on the basis of the explanation, it is difficult for students to relate technology and effect of action, as can be imagined. The use of multimedia aided teaching, teachers can take action audio-visual broadcast repeatedly, slow down, freeze, get rid of the control of spatial and temporal factors, the technology of short action unfolding in time, location in space, interspersed on the technical analysis of the key points, highlighting the teaching difficulty, which is convenient for students to establish the correct action the concept, 
strengthen the understanding of the technology, fully embodies the intuitive physical education.

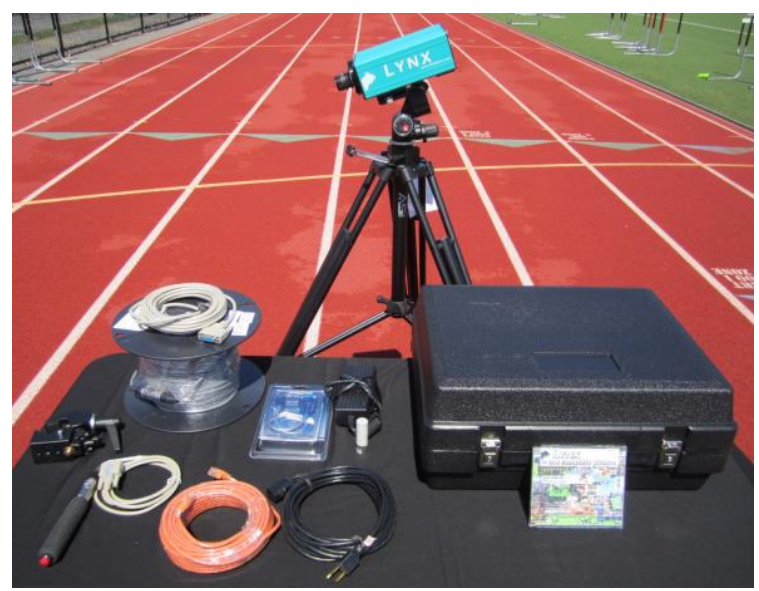

Figure 6. Track and Field Teaching Video

Physical education has its own characteristics, often need the teacher's words and deeds, because teachers' individual differences exist (such as physical quality, age, special exercise capacity, etc.), and track and field projects and more complex technology. The sports ability requirements, running, jumping and throwing three big differences, so that a teacher is very difficult to make the technical movement athletics all make accurate demonstration and explanation, in practice, is a fear of mistakes, even for materials due to subjective reasons, self-assertion to choose or do things carelessly. The use of multimedia assisted teaching, we can avoid this problem, reduce teachers work intensity and pressure, make up the defects of teachers' ability, presenting to students are modern, advanced and accurate technical demonstration, concise and focused on, on the basis of the students' practice, give full play to the leading role of Teachers in teaching in. The production of IA $\mathrm{C}$ courseware must be the crystallization of the collective wisdom of teachers. A number of experienced teachers, in the collection, sorting, editing courseware, not only enrich their knowledge, broaden their horizons and deepen; communicate with each other, a process of collective preparation, so that not only improves the teaching effect, but also improve the quality of teachers.

In the process of learning sports skills in the use of multimedia assisted teaching methods, increase the amount of information to the students' output, depending on the students, listen, touch and proprioceptive organs such as the full range of multi-sensory stimulation, which is convenient for students to accept the knowledge transfer, nonintellectual factors, to avoid or reduce the errors of interference in the formation of motor skills and enhance the students on the structure and action moves the internal connection between understanding and mastering, reduce motor memory forgetting amount, thus speeding up the formation of motor skills and knowledge, at the same time, because of the correct technique to their solution, and greatly improve the ability to analyze and solve problems. Athletics is relatively boring, the use of multimedia assisted teaching, you can create a good teaching atmosphere. The high level of competition, technology demonstration and beautiful, vivid picture, wonderful show slow motion, special magic, illustrated the technical analysis and so on, make the teaching more vivid, so as to stimulate the students' learning interest and desire for knowledge, reduce the difficulty of learning, so that students on track and field skills learning can see, see understand, easy to understand and remember it, improve the consciousness of the students' learning enthusiasm. Not only obtained a good teaching effect, under the same conditions, because of the good technical action, but also the relative improvement of the 
students' ability to exercise, in turn, will promote the students' favorite track and field sports.

\section{Influence of Multimedia on the Teaching of Track and Field Teaching}

\subsection{Multimedia Track and Field Teaching}

The track and field teaching requirements are relatively high for the production of multimedia courseware, and the multimedia courseware tools more powerful, coupled with the rich Internet material, produced the desired track and field teaching of multimedia courseware is not difficult. The multimedia courseware making tools mainly include Microsoft PowerPoint, Author Ware, master of multimedia courseware authoring system. In the reality of teaching in the field of multimedia track and field teaching courseware is very strong, it can be the teacher in the reality of the problems encountered in teaching and difficult to express the intent of a comprehensive, systematic, intuitive to show up. At the same time, a strong interaction to enable students and teachers to communicate more smoothly, for the track and field sports focus, difficult action to see more thoroughly, remember more firmly, can build a complete action essentials.

Table 1. Technical Evaluation Experiment Comparison

\begin{tabular}{|l|l|l|l|}
\hline group & number & Technical evaluation results & pass rate \\
\hline Experience group & 60 & $72 \pm 1.4$ & $83 \%$ \\
\hline control group & 60 & $68 \pm 1.4$ & $76 \%$ \\
\hline difference & 0 & 4 & $7 \%$ \\
\hline
\end{tabular}

Table 2. Experimental Comparison of Sports Performance

\begin{tabular}{|c|c|c|c|c|}
\hline group & number & Athletic performance & $\mathrm{F}$ & $\mathrm{P}$ \\
\hline Experience group & 60 & 77.15 & \multirow{2}{*}{4.312} & 0.000 \\
\hline control group & 60 & 73.24 & & \\
\hline
\end{tabular}

\subsection{Difficulties and Countermeasures of Multimedia Teaching in Track and Field}

There are also difficulties in the application of multimedia technology in the track and field teaching of sports colleges and universities in China. Research shows that $84 \%$ teachers in the field of track and field theory teaching has had the experience of using multimedia courseware. But in the use of the effect, there is a big gap. $63 \%$ teachers in the questionnaire, the use of courseware after the harvest is not. In the effect of classroom teaching, multimedia courseware assisted teaching is not as good as the traditional teaching mode. $52 \%$ teachers think that in the process of multimedia teaching, it still plays the role of traditional teachers, but cannot adapt to the requirements of modern teaching. In the survey found that only $31 \%$ of teachers skilled in multimedia technology. The data showed that: $74 \%$ of the students cannot adapt to the multimedia teaching method, when applied to multimedia teaching, students don't have enough time to take notes, some students like watching movies, listening to a class have almost forgotten, and no notes don't speaking the content under review. Thus its learning effect is greatly reduced.

The problems that arise in the use of multimedia technology are: (1) teachers' subjective factors. The teacher teaching idea obsolete, in the courseware design process does not consider whether to choose the appropriate teaching content, emphasis is not prominent, even mistakenly think that the courseware is simply the knowledge points to the projector, instead of the traditional chalk; there are some teachers to use computer 
skilled, simply abandoned. All of these affect the application of multimedia technology. (2) the objective factors of multimedia itself. Skillfully master the multimedia technology is a challenge for teachers, as a kind of information technology products, should be more reasonable and humane design space. (3) the students' adaptation to multimedia technology. For new things, from exposure to acceptance is a process of psychological cognition. The features and advantages of multimedia technology in track and field teaching and problems, the author suggests, to find the combining point and the application of multimedia technology in the teaching process of track and field, promote the reform and development of track and field teaching, strengthen teacher external multimedia technology training and improve modernization in education reform continue to promote in-depth teaching means.

- To raise the importance of the teaching of track and field technology: Education departments and universities should be paid more attention to the track and field teaching, multimedia aided teaching means investment guarantee funds for education, with higher levels of hardware and software materials, reasonable arrangements for the use of the existing classroom; the curriculum, courses and practice courses to better track and field teaching to combine the use of Multimedia equipment for example, multimedia equipment installed directly in the training place, make full use of the two be made one, audio-visual equipment resources; teacher professional development, teachers attention to research opportunities, making multimedia courseware to broaden horizons, give full play to various functions of multimedia equipment, serve for the teaching, deepening teaching reform.

- Education idea and vocational skill training: At present, many sports colleges and universities are popularizing the computer hardware equipment, but they ignore the teacher's computer basic knowledge training, so as to lack the essence of the theory. In the ideological concept and practical application, are not very well adapted to. Therefore, it is very important to popularize the theory knowledge of teachers' application in the field of computer aided track and field technology.

- Promote teachers' professional development: To improve the skills and theoretical knowledge in the teaching of track and field. The improvement of teaching skills benefit from the correct cognitive orientation, which can promote the deepening of theoretical cognition through practice. Therefore, in the course of track and field teaching in multimedia should be infiltrated into the teaching process, focus on strengthening the students' cognitive and cognitive orientation through the guidance of the correct practice, reduce the mistakes in exercises, master the skills. The advantage of multimedia technology is also an effective means to develop students' theoretical knowledge. Pay attention to teachers' collective lesson preparation and discuss the importance of making multimedia courseware. Multimedia courseware resources should be well is the crystallization of the collective wisdom of teachers, at the same time the collective preparation of lessons and making courseware, also increase the communication between teachers, which makes the teaching resources of track and field course is more abundant, more effective teaching methods, teaching design innovation, teaching effect is better, the teacher has achieved the sharing of resources and objective learn from each other.

\section{Conclusions}

With the reform of track and field teaching at home and abroad, the adjustment of curriculum theory and practice lesson proportion is the increase in the basic theory represent the general trend, the class hours, how to ensure the students' practical ability is 
improved effectively is a major problem faced by teachers. A lot of teachers are more important than the classroom teaching in class, and many years of teaching habits formed the dependence of traditional teaching methods, ignoring the cultivation of students' ability, leading to the enthusiasm of students' autonomous learning is not high. With the acceleration of the process of educational modernization, computer technology has been widely used in the classroom. Practice has proved that it is feasible to apply multimedia aided teaching in college track and field teaching, which is in line with the direction of the current education and teaching reform. The use of multimedia technology teaching means to improve the quality of teaching has a lot of space, but also need to continue to study and explore the physical education teachers, so that multimedia technology in physical education to fully play its role.

\section{References}

[1] S. Jian-hua and L. hong, "Explore the Effective Use of Multimedia Technology in College Physics Teaching", Energy Procedia, vol. 17, (2012), pp. 1897-1900.

[2] R. A. Sabella, "School counselors perceived importance of counseling technology competencies", Computers in Human Behavior, vol. 26, (2010), pp. 609-617.

[3] N. R. Mastroleo and R. Turrisi, "Examination of posttraining supervision of peer counselors in a motivational enhancement intervention to reduce drinking in a sample of heavy-drinking college students", Journal of Substance Abuse Treatment, vol. 39, (2010), pp. 289-297.

[4] Z. Huang and M. Benyoucef, "From e-commerce to social commerce: A close look at design features", Electronic Commerce Research and Applications, vol. 12, no. 4, (2013), pp. 246-259.

[5] C. Zhang and X. Chen, "Use of Multimedia in Gross Infective Pathogen Experimental Teaching", Procedia Engineering, vol. 37, (2012), pp. 64-67.

[6] C. Krstev, and A. Trtovac, "Teaching Multimedia Documents to LIS Students", The Journal of Academic Librarianship, vol. 40, no. 2, (2014), pp.152-162.

[7] W. Dai, L. Fan, "Discussion about the Pros and Cons and Recommendations for Multimedia Teaching in Local Vocational Schools", Physics Procedia, Vol.33, (2012), pp.1144-1148.

[8] R. Khansa, "Teachers' Perceptions toward School Counselors in Selected Private Schools in Lebanon", Procedia - Social and Behavioral Sciences, Vol.185, (2015), pp.381-387. 